\title{
Effectiveness of a Clinical Pharmacist Medication Therapy Management Program in Discontinuation of Drugs to Avoid in the Elderly
}

\author{
Nicole Caffiero, PharmD; Thomas Delate, PhD, MS; Mercy D. Ehizuelen, PharmD; and Kris Vogel, RPh
}

\section{ABSTRACT}

BACKGROUND: Despite evidence of fall risk associated with some drugs to avoid in the elderly (DAEs), many aged patients continue to receive them.

OBJECTIVE: To assess the effectiveness of a clinical pharmacist medication therapy management program (MTM) on discontinuation of prescribed DAEs.

METHODS: This was a retrospective cohort study conducted at an integrated health care delivery system. Kaiser Permanente Colorado beneficiaries aged $\geq 65$ years who were MTM-eligible and targeted for a DAE dispensing between 01/01/2015 and 09/30/2015 were included in the observation group. Medicare beneficiaries who were not eligible for MTM but had a targeted DAE dispensing during the same time period were included in the control group. The percentage of patients with another DAE dispensing of the same specified medication (no matter the strength) during the 100 days following index DAE dispensing was assessed. Univariate and multivariable logistic regression analyses were conducted.

RESULTS: A total of 9,059 Medicare beneficiaries were included, with 226 beneficiaries in the MTM group and 8,833 beneficiaries in the non-MTM group. Beneficiaries were primarily female and white and had a high burden of chronic disease. The percentages of patients with another dispensing of the specified DAE were $7.1 \%(95 \% \mathrm{Cl}=3.7 \%-10.4 \%)$ for the MTM beneficiaries and $35.3 \%$ (95\% $\mathrm{Cl} 34.2 \%-36.2 \%$ ) for the non-MTM beneficiaries $(P<0.001)$. The $0 \mathrm{R}$ for the MTM group to have received another dispensing of the specified DAE was $0.12(95 \% \mathrm{Cl}=0.08-0.22)$ with adjustment for potential confounders.

CONCLUSIONS: A clinical pharmacist-provided MTM intervention was associated with decreased DAE dispensing in Medicare beneficiaries. Future studies should evaluate means to further decrease DAE use in the aged.

J Manag Care Spec Pharm. 2017;23(5):525-31

Copyright $\odot 2017$, Academy of Managed Care Pharmacy. All rights reserved.

\section{What is already known about this subject}

Evidence suggests that some drugs to avoid in the elderly (DAEs) are associated with falls in aged patients. Despite the evidence of fall risk with these medications, many patients continue to receive them

Although health plans are implementing various procedures to reduce DAE use, there is limited evidence on means to reduce successfully the use of these medications.

\section{What this study adds}

Medicare beneficiaries who had received a DAE and were targeted for medication therapy management (MTM) by a clinical pharmacist had another dispensing of the specified DAE at a 100-day rate of $7.1 \%$, while beneficiaries who had received a DAE but were not targeted for MTM had another dispensing of the specified DAE at a 100 -day rate of $35.3 \%$.

Beneficiaries who were targeted for MTM had an adjusted 88\% reduced risk of another dispensing of the specified DAE.

These findings suggest that clinical pharmacist-provided MTM is an important and effective tool to decrease high-risk medication use in the aged.

ertain classes of the so-called drugs to avoid in the elderly (DAEs) are associated with falls in patients $\geq 65$ years of age (aged patients)., Falls are associated with high-cost health care utilization, and by 2020 , it is estimated that the cost of falls will be $\$ 55$ billion annually in the United States. ${ }^{3}$ Despite the evidence of fall risk with DAE use, many aged patients continue to receive them, ${ }^{4}$ with the average aged patient being dispensed $>2$ of these medications chronically. ${ }^{5}$ It has been suggested that discontinuing DAEs may be effective for fall prevention. ${ }^{3}$

Unfortunately, there is limited evidence on how to reduce the use of DAEs. ${ }^{6}$ Current guidelines suggest having a health care provider review aged patients' high-risk medications to identify ones that can be discontinued. ${ }^{1}$ One way to accomplish medication reviews is through pharmacist-provided medication therapy management programs (MTM). For patients who meet risk criteria, MTM programs focus on educating patients regarding high-risk medications, improving adherence to medications, and optimizing medication therapy. ${ }^{3}$

Clinical pharmacists in the Kaiser Permanente Colorado (KPCO) Clinical Pharmacy Call Center (CPCC) perform telephone-based MTM for KPCO's Medicare beneficiaries who have met MTM qualifying criteria. Patients enrolled in the CPCC's MTM program were eligible for an annual comprehensive medication review and quarterly targeted medication reviews where appropriate discontinuation of DAEs is a program priority. The purpose of this study was to assess the 


\begin{tabular}{|c|c|c|}
\hline Class & \multicolumn{2}{|c|}{ Medication } \\
\hline \multirow{3}{*}{$\begin{array}{l}\text { Analgesic and } \\
\text { anesthetic }\end{array}$} & Butalbital compound & Ketorolac \\
\hline & Diphenhydramine & Meperidine \\
\hline & Indomethacin & Pentazocine \\
\hline Antineoplastic & Megestrol & \\
\hline \multirow[t]{5}{*}{ Cardiovascular } & Digoxin & Methyldopa \\
\hline & Disopyramide & Methyldopate \\
\hline & Guanabenz & Nifedipine \\
\hline & Guanfacine & Reserpine \\
\hline & Isoxsuprine & \\
\hline \multirow{10}{*}{$\begin{array}{l}\text { Central nervous } \\
\text { system }\end{array}$} & Amitriptyline & Imipramine \\
\hline & Amobarbital & Mephobarbital \\
\hline & Butabarbital & Meprobamate \\
\hline & Chloral hydrate & Pentobarbital \\
\hline & $\begin{array}{l}\text { Chlordiazepoxide } \\
\text { amitriptyline }\end{array}$ & Phenobarbital \\
\hline & Clomipramine & Secobarbital \\
\hline & Doxepin & Thioridazine \\
\hline & Ergoloid mesylates & Trimipramine \\
\hline & Eszopiclone & Zaleplon \\
\hline & Hydroxyzine & Zolpidem \\
\hline \multirow{5}{*}{$\begin{array}{l}\text { Endocrine and } \\
\text { metabolic }\end{array}$} & Chlorpropamide & Estradiol acetate \\
\hline & Conjugated estrogens & Estropipate \\
\hline & Desiccated thyroid & Glyburide \\
\hline & Esterified estrogens & Glyburide-metformin \\
\hline & Estradiol & \\
\hline Gastrointestinal & Trimethobenzamide & \\
\hline Genitourinary & Nitrofurantoin & \\
\hline Hematologic & Dipyridamole & Ticlopidine \\
\hline \multirow[t]{4}{*}{ Neuromuscular } & Benztropine & Metaxalone \\
\hline & Carisoprodol & Methocarbamol \\
\hline & Chlorozoxazone & Orphenadrine \\
\hline & Cyclobenzaprine & Trihexyphenidyl \\
\hline \multirow[t]{6}{*}{ Respiratory } & Bropheniramine & Dexclorpheniramine \\
\hline & Carbinoxamine & Diphenhydramine \\
\hline & Chlorpheniramine & Doxylamine \\
\hline & Clemastine & Promethazine \\
\hline & Cyproheptadine & Tripolidine \\
\hline & Dexbrompheniramine & \\
\hline
\end{tabular}

effectiveness of the CPCC's MTM to discontinue prescribed DAEs for Medicare beneficiaries. Assessing the effectiveness of MTM medication reviews is needed to identify interventions that can reduce DAE use in the aged.

\section{Methods}

\section{Study Design and Setting}

This was a retrospective cohort study of Medicare beneficiaries who were dispensed a DAE (Table 1) between January 1, 2015, and September 30, 2015.7 Beneficiaries were followed for 100 days after the DAE dispensing to assess for discontinuation of their DAE. If a beneficiary had more than 1 unique DAE dispensed during the study period, only the DAE dispensed most proximal to the study end date was included in the study. The dispensing date of the included DAE was considered the study index date.

This study was conducted at KPCO, an integrated health care delivery system providing care to over 600,000 members in Colorado at 29 outpatient medical offices at the time of the study. The CPCC at KPCO provides telephonic, pharmacistprovided MTM with comprehensive medication reviews for patients who meet predefined criteria. KPCO utilizes an outpatient electronic health record (EHR) that provides e-prescribing capabilities and interfaces with the internal pharmacy and laboratory systems. Coded and free-text medical, pharmacy, laboratory, emergency department (ED), hospitalization, and membership information from within the delivery system, as well as from other contracted and affiliated facilities, are captured in KPCO's administrative and claims databases. All aspects of this study were reviewed and approved by the KPCO Institutional Review Board.

\section{Study Population}

Medicare beneficiaries who had a DAE dispensed between January 1, 2015, and September 30, 2015, and were aged 65 years and older at the time of dispensing were included. The observation group (MTM group) included KPCO Medicare beneficiaries who were eligible for MTM services (e.g., $\geq 5$ Medicare Part D medications in a specified drug class, $\geq 3$ specified comorbidities, and costs covered by Medicare Part D that were $\geq \$ 3,318$ ) and had at least 1 DAE dispensed during the study period. The control group (non-MTM group) included KPCO Medicare beneficiaries who were not eligible for MTM services but had at least 1 DAE dispensed during the study period. Beneficiaries who had received hospice or palliative care or care in a skilled nursing or long-term care facility at the time that their DAE was dispensed were not included. In addition, beneficiaries had to have remained a KPCO member for at least 100 days after their index DAE dispensing date.

\section{Intervention}

The KPCO MTM program is based on the American Pharmacists Association/National Association of Chain Drug Stores Foundation core elements for MTM service model. ${ }^{8}$ The comprehensive medication review during KPCO's MTM program consisted of a telephonic, interactive discussion between a clinical pharmacist and beneficiary to assess medication therapies. Pharmacist-beneficiary conversations during a medication review vary, as there is not specific scripting that each pharmacist must follow. Pharmacists are trained to use their clinical knowledge and judgment to engage each beneficiary individually. The conversation is beneficiary- and medicationspecific and usually consists of a risk-to-benefit conversation about the medication and any advice for safer alternatives. An 
TABLE 2 Patient Characteristics by Reception of MTM Status

\begin{tabular}{|c|c|c|c|c|c|c|c|}
\hline \multirow{2}{*}{$\begin{array}{l}\text { Characteristic } \\
\text { Mean age, years (SD) }\end{array}$} & \multicolumn{2}{|c|}{$\begin{array}{c}\text { Overall } \\
\mathrm{N}=9,059\end{array}$} & \multicolumn{2}{|c|}{$\begin{array}{c}\text { MTM } \\
\mathbf{n}=226\end{array}$} & \multicolumn{2}{|c|}{$\begin{array}{c}\text { Non-MTM } \\
\mathrm{n}=8,833\end{array}$} & \multirow{2}{*}{$\begin{array}{c}\boldsymbol{P} \text { Value } \\
0.225\end{array}$} \\
\hline & 73.0 & $(6.9)$ & 72.2 & $(6.2)$ & 73.1 & $(6.9)$ & \\
\hline Female sex, n (\%) & 6,375 & $(70.4)$ & 137 & $(60.6)$ & 6,238 & $(70.6)$ & 0.001 \\
\hline Mean CDS (SD) & 4.2 & $(3.5)$ & 6.6 & $(4.5)$ & 4.2 & (3.4) & $<0.001$ \\
\hline Mean count of unique prescription medications (SD) & 7.0 & (4.4) & 10.5 & (6.9) & 6.9 & $(4.2)$ & $<0.001$ \\
\hline Mean CCI (SD) & 1.7 & $(2.2)$ & 3.3 & $(2.4)$ & 1.6 & $(2.4)$ & $<0.001$ \\
\hline Medicaid cobeneficiary, n (\%) & 191 & $(2.1)$ & 13 & $(5.8)$ & 178 & $(2.0)$ & $<0.001$ \\
\hline Race, n (\%) & & & & & & & $<0.001$ \\
\hline White & 7,323 & $(80.8)$ & 151 & $(66.8)$ & 7,172 & $(81.2)$ & \\
\hline Other & 713 & $(7.9)$ & 15 & $(6.6)$ & 698 & $(7.9)$ & \\
\hline Unknown/unreported & 1,023 & $(11.3)$ & 60 & $(26.6)$ & 963 & $(10.9)$ & \\
\hline Hispanic ethnicity, n (\%) & & & & & & & $<0.001$ \\
\hline Yes & 660 & (7.3) & 15 & $(6.6)$ & 645 & (7.3) & \\
\hline No & 7,789 & $(86.0)$ & 158 & $(69.9)$ & 7,631 & $(86.4)$ & \\
\hline Unknown/unreported & 610 & $(6.7)$ & 53 & $(23.5)$ & 557 & $(6.3)$ & \\
\hline \multicolumn{8}{|l|}{ Comorbidities, n (\%) } \\
\hline Cerebrovascular disease & 380 & $(4.2)$ & 21 & (9.3) & 359 & $(4.1)$ & $<0.001$ \\
\hline Congestive heart failure & 1,049 & (11.6) & 44 & $(19.5)$ & 1,005 & (11.4) & $<0.001$ \\
\hline Dementia & 209 & $(2.3)$ & 10 & $(4.4)$ & 199 & $(2.3)$ & 0.032 \\
\hline Diabetes & 1,615 & $(17.8)$ & 115 & $(50.9)$ & 1,500 & $(17.0)$ & $<0.001$ \\
\hline Renal disease & 1,806 & (19.9) & 86 & $(38.1)$ & 1,720 & $(19.5)$ & $<0.001$ \\
\hline Alcohol abuse history, n (\%) & 62 & $(0.7)$ & 0 & $(0.0)$ & 62 & $(0.7)$ & 0.206 \\
\hline Drug abuse history, n (\%) & 5 & $(0.1)$ & 0 & $(0.0)$ & 5 & $(0.1)$ & 0.721 \\
\hline KPCO service area, n (\%) & & & & & & & $<0.001$ \\
\hline Colorado Springs & 418 & (4.6) & 48 & $(21.2)$ & 370 & $(4.2)$ & \\
\hline Denver/Boulder & 8,018 & $(88.5)$ & 144 & $(63.7)$ & 7,874 & $(89.1)$ & \\
\hline Northern Colorado & 426 & $(4.7)$ & 5 & $(2.2)$ & 421 & $(4.8)$ & \\
\hline Pueblo & 197 & $(2.2)$ & 29 & $(12.8)$ & 168 & $(1.9)$ & \\
\hline Mean percentage of household with at least some college education (SD) & 69.2 & $(17.1)$ & 66.4 & $(16.5)$ & 69.3 & $(17.1)$ & 0.015 \\
\hline Mean family income (SD) & $\$ 88,282$ & $(\$ 36,912)$ & $\$ 79,612$ & $(\$ 29,548)$ & $\$ 88,505$ & $(\$ 37,057)$ & 0.005 \\
\hline
\end{tabular}

example of a pharmacist's conversation point could be, "I have discussed this with your doctor and due to the risk of using this medication, your doctor would like to change your medication from $x$ to $y$." If the beneficiary is in agreement, the pharmacist works with the beneficiary's prescriber to move forward with the change in medication. The pharmacist accomplishes drug therapy changes via communication with the prescriber within the EHR or by fax. A final written summary of any changes is sent to the beneficiary in a standardized written format. This process also includes prescriber education to promote an understanding of why any recommended change is appropriate with an emphasis on promotion of coordinated care.

\section{Study Outcomes}

The primary outcome was a comparison between groups of the percentage of patients who had the specified DAE dispensed during the 100 days after the index DAE dispensing date. An outcome was a dispensing of the same specified DAE (no matter the strength) dispensed in the 100 days after the index DAE dispensing date. The 100-day follow-up was chosen since the vast majority of KPCO Medicare beneficiaries have a defined 30-day supply prescription drug benefit (unless using mailorder pharmacy for a 90-day supply) and to account for beneficiaries who may have had an extra supply from previous fills or for plan benefits (e.g., retirees covered under their employer's Medicare plan) that allow dispensing of a >90-day supply. Descriptions and comparisons of index and follow-up DAE medications are presented. Multivariable logistic regression modeling of DAE discontinuation was performed to control for potential confounding factors.

\section{Data Collection}

Information on beneficiary characteristics (e.g., date of birth, sex, race, ethnicity, Medicare/Medicaid status) and comorbidity diagnoses recorded during the 180 days prior to the index date (baseline) were obtained from queries of KPCO's electronic administrative and claims databases. Information on beneficiaries who were targeted for a medication review for a 
TABLE 3 Index Drugs to Avoid in the Elderly Medication Class by Reception of MTM Status

\begin{tabular}{|c|c|c|c|c|c|c|c|}
\hline \multirow{2}{*}{$\begin{array}{l}\text { Medication Class, } \mathbf{n}(\%) \\
\text { Analgesic and anesthetic } \\
\end{array}$} & \multicolumn{2}{|c|}{$\begin{array}{c}\text { Overall } \\
\mathrm{N}=9,059\end{array}$} & \multicolumn{2}{|c|}{$\begin{array}{c}\text { MTM } \\
\mathrm{n}=226\end{array}$} & \multicolumn{2}{|c|}{$\begin{array}{c}\text { Non-MTM } \\
\mathrm{n}=8,833\end{array}$} & \multirow{2}{*}{$\frac{P \text { Value }}{0.604}$} \\
\hline & 555 & (6.1) & 12 & (5.3) & 543 & $(6.2)$ & \\
\hline Antineoplastic & 206 & $(2.3)$ & 14 & $(6.2)$ & 192 & $(2.2)$ & $<0.001$ \\
\hline Central nervous system & 2,030 & $(22.4)$ & 47 & $(20.8)$ & 1,983 & $(22.5)$ & 0.556 \\
\hline Cardiovascular & 1,667 & $(18.4)$ & 36 & $(15.9)$ & 1,631 & $(18.5)$ & 0.331 \\
\hline Endocrine and metabolic & 2,007 & $(22.2)$ & 55 & $(24.3)$ & 1,952 & $(22.1)$ & 0.424 \\
\hline Gastrointestinal & 83 & $(0.9)$ & 1 & $(0.4)$ & 82 & $(0.9)$ & 0.725 \\
\hline Genitourinary & 1,271 & $(14.0)$ & 4 & (1.8) & 1,267 & $(14.3)$ & $<0.001$ \\
\hline Hematologic & 13 & $(0.1)$ & 3 & (1.3) & 10 & $(0.1)$ & 0.003 \\
\hline Neuromuscular & 828 & $(9.1)$ & 45 & $(19.9)$ & 783 & $(8.9)$ & $<0.001$ \\
\hline Respiratory & 399 & (4.4) & 9 & $(4.0)$ & 390 & $(4.4)$ & 0.754 \\
\hline
\end{tabular}

DAE dispensing, their targeted DAE, and the date of DAE dispensing were obtained from the CPCC's MTM tracking database. Information on DAE dispensings for beneficiaries who were not MTM eligible was obtained from electronic queries of the KPCO administrative pharmacy database using National Drug Codes. Information on study outcomes was obtained from queries of the KPCO administrative pharmacy database during the 100-day follow-up. Samples of extracted data were verified for accuracy by manual chart review.

\section{Statistical Analysis}

It was estimated that there would be 150 beneficiaries who were MTM eligible and had a DAE dispensed during the study period and 1,200 beneficiaries who were not MTM eligible and had a DAE dispensed during the study period. With these estimated group sizes, a minimum phi coefficient value of 0.06 (e.g., $15 \%$ and $10 \%$ of beneficiaries with a follow-up DAE dispensing in the observation and control groups, respectively) could be detected with $80 \%$ power at a 2-sided alpha of 0.05 .

Age was calculated as of date of DAE dispensing. The count of unique medications per patient was calculated using the first 8 digits of the Generic Product Identifier code from all medication dispensings during baseline. A chronic disease score (CDS), an indicator of a patient's burden of chronic illness and predictor of future health care utilization, was calculated from each beneficiary's prescription dispensing history during baseline. ${ }^{9}$ The Charlson Comorbidity Index (CCI), a comorbidity prognosis score, was calculated from each beneficiary's diagnosis history during baseline. ${ }^{10} \mathrm{~A}$ follow-up DAE medication dispensing was operationalized as at least 1 additional purchase of the same DAE medication (no matter the strength; yes/no) during the 100 days following the specified DAE index dispensing date.

Patient characteristics are reported as means and standard deviations for interval-level variables (e.g., age) and percentages for categorical variables (e.g., sex, Medicaid status). The percentage of patients in each group with a follow-up DAE dispensing is reported with its $95 \%$ confidence interval (CI). Univariate analyses were conducted to assess for differences between groups using chi-square tests of association/Fisher's exact tests, as applicable, for categorical variables and t-tests (or nonparametric equivalent, as applicable) for continuous variables. Multivariable logistic regression modeling with adjustment for potential confounders (as determined with clinical and statistical judgment) was conducted on the follow-up DAE dispensing outcome. Potential confounders included age, sex, KPCO service area, CDS, CCI, Medicaid status, education status, family income, count of unique medication dispensings during baseline, antineoplastic DAEs, neuromuscular DAEs, cerebrovascular disease, congestive heart failure, diabetes, renal disease, and dementia. The odds ratios (ORs) and their 95\% CIs are reported.

\section{Results}

A total of 9,059 Medicare beneficiaries were included, with 226 beneficiaries in the MTM group and 8,833 beneficiaries in the non-MTM group. Beneficiaries were primarily female and white and had a high burden of chronic disease (Table 2). Beneficiaries in the MTM group were more likely to be male $(P=0.001)$, have an unknown/unreported race and Hispanic ethnicity $(P<0.001)$, be from outside KPCO's Denver/Boulder service area $(P<0.001)$, be a Medicaid cobeneficiary, have a higher burden of disease and comorbidities, and have a higher count of unique medication dispensings during baseline (all $P<0.05)$. Beneficiaries in the MTM group had higher household education $(P=0.015)$ and family income $(P=0.005)$.

Beneficiaries in the MTM group were more likely to have been dispensed an antineoplastic (e.g., megestrol), hematologic (e.g., dipyridamole), and neuromuscular DAE, while patients in the non-MTM group were more likely to have been dispensed a genitourinary (e.g., nitrofurantoin) DAE (Table 3). For the beneficiaries with an index neuromuscular DAE, there were no differences between the MTM $(n=45)$ and non-MTM $(n=783)$ 
TABLE 4 Drugs to Avoid in the Elderly Medication Classes with a Follow-up Dispensing by Reception of MTM Status

\begin{tabular}{|c|c|c|c|c|c|c|c|}
\hline \multirow{2}{*}{$\begin{array}{l}\text { Medication Class, } \mathbf{n}(\%) \\
\text { Analgesic and anesthetic }\end{array}$} & \multicolumn{2}{|c|}{$\begin{array}{c}\text { Overall } \\
\mathrm{N}=3,121\end{array}$} & \multicolumn{2}{|c|}{$\begin{array}{l}\text { MTM } \\
\mathbf{n}=16\end{array}$} & \multicolumn{2}{|c|}{$\begin{array}{l}\text { Non-MTM } \\
\mathrm{n}=3,105\end{array}$} & \multirow{2}{*}{$\frac{P \text { Value }}{0.096}$} \\
\hline & 103 & $(3.3)$ & 2 & $(12.5)$ & 101 & $(3.3)$ & \\
\hline Antineoplastic & 55 & (1.8) & 1 & $(6.3)$ & 54 & (1.7) & 0.248 \\
\hline Central nervous system & 678 & $(21.7)$ & 3 & $(18.8)$ & 675 & $(21.7)$ & 0.772 \\
\hline Cardiovascular & 1,030 & $(33.0)$ & 2 & $(12.5)$ & 1,028 & $(33.1)$ & 0.109 \\
\hline Endocrine and metabolic & 956 & $(30.6)$ & 4 & $(25.0)$ & 952 & $(30.7)$ & 0.789 \\
\hline Gastrointestinal & 55 & (1.8) & 1 & (6.3) & 54 & (1.7) & 0.248 \\
\hline Genitourinary & 75.4 & $(14.0)$ & 0 & $(0.0)$ & 75 & $(2.4)$ & 0.529 \\
\hline Hematologic & 3 & $(0.1)$ & 1 & $(6.3)$ & 2 & $(0.1)$ & 0.015 \\
\hline Neuromuscular & 133 & $(4.3)$ & 1 & $(6.3)$ & 132 & $(4.3)$ & 0.502 \\
\hline Respiratory & 33 & $(1.1)$ & 1 & $(6.3)$ & 32 & $(1.1)$ & 0.157 \\
\hline
\end{tabular}

MTM = medication therapy management.

groups in benztropine ( $4.4 \%$ vs. $2.4 \%$ ), carisoprodol (6.7\% vs. $3.5 \%)$, cyclobenzaprine (60.0\% vs. $70.1 \%)$, methocarbamol ( $17.8 \%$ vs. $20.1 \%$ ), orphenadrine (0.0\% vs. $0.4 \%$ ), and trihexyphenidyl $(0.0 \%$ vs. $1.8 \%$ ) DAEs (all $P>0.05)$. Beneficiaries in the MTM group were more likely to have had an index metaxalone DAE dispensing ( $11.1 \%$ vs. $1.8 \%, P<0.001)$.

The percentages of beneficiaries with a follow-up dispensing of the specified DAE were $7.1 \%$ (95\% CI=3.7\%-10.4\%, $\mathrm{n}=16$ ) for the MTM group and $35.2 \%$ (95\% CI=34.2\%-36.2\%, $\mathrm{n}=3,105)$ for the non-MTM group $(P<0.001)$. Of the 16 beneficiaries in the MTM group and 3,105 patients in the nonMTM group with a follow-up DAE dispensing, 8 (50.0\%) and 815 (26.3\%) beneficiaries in the MTM and non-MTM groups, respectively, had more than 1 dispensing of the specified DAE during follow-up $(P=0.032)$. The mean days supply for their DAE during follow-up was $78.6( \pm 27.9)$ and $77.7( \pm 23.8)$ for the MTM and non-MTM groups, respectively $(P=0.451)$. Cardiovascular and endocrine/metabolic DAEs were the most common medication classes for the follow-up DAE dispensings (Table 4). Beneficiaries in the MTM group were more likely to have had a hematologic DAE follow-up dispensing (6.3\% vs. $0.01 \%, P=0.015)$ while all other DAE medication class followup dispensing percentages were equivalent (all $P>0.05$ ).

The OR for the MTM group to have had a dispensing of the specified DAE during follow-up was 0.12 (95\% CI=0.08-0.22) with adjustment for age, sex, KPCO service area, CDS, CCI, Medicaid status, education status, family income, antineoplastic DAE, neuromuscular DAE, count of unique medication dispensings during baseline, cerebrovascular disease, congestive heart failure, diabetes, renal disease, and dementia (Table 5). A diagnosis of congestive heart failure $(\mathrm{OR}=1.57,95 \% \mathrm{CI}=1.34-1.84)$ and the beneficiary being from the Colorado Springs service area $(\mathrm{OR}=1.38,95 \% \mathrm{CI}=1.11-1.71)$ were the factors most strongly associated with having had a dispensing of the specified DAE during follow-up.

\section{Discussion}

This retrospective analysis of $>9,000$ Medicare beneficiaries who were dispensed a DAE identified that the reception of MTM from a clinical pharmacist was associated with an adjusted $88 \%$ reduction in the likelihood of continuation of a specified DAE. Although health systems are incentivized to reduce DAE use in the aged, there is minimal evidence demonstrating successful interventions to accomplish such reductions. Our findings indicate that clinical pharmacist-provided MTM is an important and effective tool to decrease high-risk medication use in the aged.

Health plans are incentivized to conduct initiatives to reduce high-risk medication use in Medicare beneficiaries. ${ }^{11}$ Scott and White Health Plan's initiative to reduce high-risk medication use included screening prescription claims for high-risk medications. ${ }^{12}$ Physicians who prescribed such medications are sent a letter describing the medication's risks and an alternative medication recommendation. ${ }^{12}$ Express Scripts, a pharmacy benefit manager, has implemented a prior authorization process for 4 high-risk medication classes. Express Scripts reported that this process was identified with a modestly lower utilization rate of high-risk medications, $5.5 \%$ versus $7.4 \%$ in plans that did not have this process. ${ }^{13}$ The results from these programs have not been published in the peer-reviewed literature, leaving questions as to their validity.

Perera et al. (2011) evaluated prescriber responses to pharmacist-initiated recommendations from an MTM program for high-risk Medicare beneficiaries with high-cost medications, adherence concerns, or safety concerns..$^{14}$ Of the 1,548 recommendations made, $8.5 \%$ were related to safety concerns and $41.4 \%$ of these recommendations were accepted. ${ }^{14}$ Welch et al. (2009) examined the effectiveness of MTM on high-risk Medicare beneficiaries who did and did not opt into receiving MTM. ${ }^{15}$ Beneficiaries who opted in were less likely to die but more likely to have had a hospitalization and had an increase 


\begin{tabular}{|c|c|c|}
\hline Multivariable Lo & c Regress & n Result \\
\hline Covariate & Odds Ratio & $95 \% \mathrm{CI}$ \\
\hline MTM group & 0.12 & $0.08-0.22$ \\
\hline Age (years) & 1.02 & $1.01-1.02$ \\
\hline Female sex & 0.99 & $0.90-1.10$ \\
\hline$\overline{C D S}$ & 1.09 & $1.06-1.11$ \\
\hline Count of unique prescription medications & 0.99 & $0.98-1.01$ \\
\hline $\mathrm{CCI}$ & 0.94 & $0.91-0.97$ \\
\hline Cerebrovascular disease & 1.12 & $0.89-1.42$ \\
\hline Congestive heart failure & 1.57 & $1.34-1.84$ \\
\hline Dementia & 0.65 & $0.47-0.90$ \\
\hline Diabetes & 0.85 & $0.74-0.97$ \\
\hline Renal disease & 1.03 & $0.88-1.20$ \\
\hline \multicolumn{3}{|l|}{ Medicaid beneficiary } \\
\hline Antineoplastic DAE & 0.68 & $0.50-0.94$ \\
\hline Neuromuscular DAE & 0.37 & $0.30-0.45$ \\
\hline \multicolumn{3}{|l|}{ KPCO service area } \\
\hline Colorado Springs & 1.38 & $1.11-1.71$ \\
\hline Northern Colorado & 0.86 & $0.69-1.07$ \\
\hline Pueblo & 1.11 & $0.80-1.54$ \\
\hline $\begin{array}{l}\text { Percentage of household with at least some } \\
\text { college education }\end{array}$ & 1.26 & $0.88-1.80$ \\
\hline Family income $(\$)$ & 0.99 & $0.98-1.01$ \\
\hline
\end{tabular}

in medication costs during follow-up. ${ }^{15}$ Neither of these studies specifically assessed the effectiveness of MTM on DAE discontinuation. Moczygemba et al. (2011) analyzed the impact of a pharmacist-provided telephone MTM program on medication- and health-related problems. ${ }^{16}$ Patients who received telephonic, pharmacist-provided MTM had more medication- and health-related problems resolved; however, no differences in adherence or total drug costs were detected between groups. ${ }^{16}$ Our study did not assess adherence or drug costs; nevertheless, our findings do support that medication problems can be resolved with pharmacist-provided MTM.

Clinical pharmacists are being utilized in other health care settings to reduce potentially inappropriate medication use in the aged. Various Veterans Affairs medical centers have implemented a quality improvement project to educate providers about the potentially inappropriate medications they prescribe in the ED. ${ }^{17}$ Moss et al. (2016) reported a $47.5 \%$ reduction in the rate of potentially inappropriate medication prescribing in the aged population discharged from one Veteran Affairs ED. ${ }^{17}$ This study's findings, along with our findings, further support that pharmacists are well suited to identify, educate, and resolve inappropriate medication use.

A meta-analysis of the effect of MTM interventions among outpatients with chronic illnesses sponsored by the U.S. Agency for Healthcare Research and Quality reported that the evidence was insufficient to determine the effect of MTM interventions on most evaluated outcomes including drug therapy problems, adverse drug events, disease-specific morbidity, disease-specific or all-cause mortality, and harms (e.g., falls). ${ }^{6}$ However the meta-analysis did identify that MTM interventions improved medication appropriateness. ${ }^{6}$ Our findings align with the meta-analysis findings, as our studied MTM intervention was associated with the reduction of targeted, inappropriate medication use in the aged.

\section{Limitations}

Several limitations should be considered when interpreting the results of our study. Patients may have refilled their DAE past the 100-day follow-up, thus underestimating the percentage of patients with a DAE dispensing during our study's follow-up. If this did occur, it was likely systematic and affected both groups equally. We were also unable to assess if the patient no longer required the DAE and would not have had a DAE dispensing during follow-up without the MTM intervention. Our use of a control group likely ameliorates this concern as the percentage of patients having had the specified DAE dispensed during follow-up likely incorporates scenarios where the DAE was not continued because it was no longer needed and the prescriber recognized the DAE's potential for harm. We used a control group that was not MTM-eligible and may have been more healthy (e.g., lower CDS and CCI) than patients in the MTM group. Patients with a higher burden of illness may have been recognized by their prescriber with a greater potential for harm with DAE use, thus making them more likely to have had their DAE not continued.

We performed multivariable regression analysis to adjust for burden of illness and other potential confounders and identified that patients in the MTM group still were $88 \%$ less likely to have had the specified DAE dispensed during follow-up. Comprehensive medication review rates at KPCO were 82.3\% in 2015 for qualified MTM patients. While a beneficiary was targeted for MTM because of dispensing of the DAE, we were unable to assess if the beneficiary actually received a comprehensive medication review specific to the DAE. Not having had received a comprehensive medication review specific to the DAE is unlikely, as the CPCC was attentive to the reduction of DAE use in the aged. Finally, this study was performed in one integrated health care system, which may limit generalizability. We included a large number of beneficiaries so that a variety of patients were assessed.

\section{Conclusions}

Medicare beneficiaries who received an MTM comprehensive medication review had a decreased likelihood of a DAE dispensing during follow-up compared to Medicare beneficiaries who were not targeted for such an intervention. Results from this study suggest that MTM performed by a clinical 
pharmacist can reduce the use of inappropriate medications in Medicare beneficiaries. A new standard of care for discontinuing DAEs should be developed for beneficiaries who do not qualify for MTM. Future studies should assess such standards.

\section{Authors}

NICOLE CAFFIERO, PharmD; MERCY D. EHIZUELEN, PharmD; and KRIS VOGEL, RPh, Pharmacy Department, Kaiser Permanente Colorado, Aurora. THOMAS DELATE, PhD, MS, Pharmacy Department, Kaiser Permanente Colorado, and Department of Clinical Pharmacy, Skaggs School of Pharmacy and Pharmaceutical Sciences, University of Colorado Anschutz Medical Campus, Aurora.

AUTHOR CORRESPONDENCE: Thomas Delate, PhD, MS, Clinical Pharmacy Research Scientist, Kaiser Permanente Colorado, 16601 E. Centretech Pkwy., Aurora, CO 80011. Tel.: 303.739.3538; E-mail: tom.delate@kp.org.

\section{DISCLOSURES}

This study was funded by the Kaiser Permanente Colorado Pharmacy Department. The funder had no role in the study design, collection, analysis and interpretation of data, writing of the report, or the decision to submit the manuscript for publication. Delate has received grant funding from Janssen Pharmaceutical Companies of Johnson \& Johnson outside of this study. The authors report no other disclosures.

Delate supervised the study and had complete access to the data and takes responsibility for the data integrity. Study concept and design were contributed by Caffiero, Delate, Ehizuelen, and Vogel. Delate collected the data, assisted by the other authors, and analysis and interpretation of the data were provided by Ehizuelen and Vogel, along with Caffiero and Delate. The manuscript was written by Caffiero and Delate, with assistance from Ehizuelen and Vogel, and revised by all the authors.

Preliminary findings from this study were presented at the Mountain States Conference for Pharmacy Residents, Fellows, and Preceptors on May 13, 2016, in Salt Lake City, Utah.

\section{REFERENCES}

1. Freeland K, Thompson A, Zhao Y, Leal JE, Mauldin PD, Moran WP. Medication use and associated risk of falling in a geriatric outpatient population. Ann Pharmacother. 2012;46(9):1118-92

2. Bennett A, Gnjidic D, Gillett M, et al. Prevalence and impact of fall-riskincreasing drugs, polypharmacy, and drug-drug interactions in robust versus frail hospitalised falls patients: a prospective cohort study. Drugs Aging 2014;31(3):225-32

3. Mascia A, Touchette D, Dolor R, et al. Evaluation of a medication therapy management program in Medicare beneficiaries at high risk of adverse drug events: study methods. In: Henriksen K, Battles JB, Keyes MA, et al., eds. Advances in Patient Safety: New Directions and Alternative Approaches. Vol. 4: Technology and Medication Safety. Rockville, MD: Agency for Healthcare Research and Quality US; 2008
4. Mott D, Martin B, Breslow R, et al. The development of a communitybased, pharmacist-provided falls prevention MTM intervention for older adults: relationship building, methods and rationale. Inov Pharm. 2014;5(1):140.

5. Nightingale G, Hajjar E, Swartz B, Andrel-Sendecki J, Chapman A. Evaluation of a pharmacist-led medication assessment used to identify prevalence of and associations with polypharmacy and potentially inappropriate medication use among ambulatory senior adults with cancer. J Clin Oncol. 2015;33(13);1453-59.

6. Viswanathan M, Kahwati LC, Golin CE, et al. Medication therapy management interventions in outpatient settings: a systematic review and metaanalysis. JAMA Intern Med. 2015;175(1):76-87.

7. National Committee for Quality Assurance. HEDIS 2015 NDC lists. Use of high-risk medications in the elderly (DAE). Table DAE-A: high-risk medications. Available at: http://www.ncqa.org/hedis-quality-measurement/hedismeasures/hedis-2015/hedis-2015-ndc-license/hedis-2015-final-ndc-lists. Accessed March 21, 2017.

8. American Pharmacists Association; National Association of Chain Drug Stores Foundation. Medication therapy management in pharmacy practice: core elements of an MTM service model (version 2.0). J Am Pharm Assoc. 2008;48(3):341-53.

9. Clark DO, Von KM, Saunders K, Baluch WM, Simon GE. A chronic disease score with empirically derived weights. Med Care. 1995;33(8):783-95.

10. Quan H, Sundararajan V, Halfon P, et al. Coding algorithms for defining comorbidities in ICD-9-CM and ICD-10 administrative data. Med Care. 2005;43(11):1130-39.

11. Medicare Prescription Drug, Improvement, and Modernization Act of 2003. Pub L. 108-173. December 8, 2003. Available at: https://www.gpo.gov/ fdsys/pkg/PLAW-108publ173/content-detail.html. Accessed April 3, 2017.

12. Luebbart C. High risk medication formulary changes for Medicare members. Scott and White Health Plan. December 4, 2015. Available at: http:// hpcms.azurewebsites.net/Portals/0/Files/Forms/Friday\%20Focus/High\%20 Risk\%20Medications.pdf?timestamp=1450287225258. Accessed April 3, 2017.

13. Rabbitt R. Keep seniors safe from high-risk meds. 2013. Available at: http://lab.express-scripts.com/insights/drug-safety-and-abuse/keep-seniorssafe-from-high-risk-meds. Accessed August 14, 2016.

14. Perera P, Guy M, Sweaney A, Boesen K. Evaluation of prescriber responses to pharmacist recommendations communicated by fax in a medication therapy management program. J Manag Care Pharm. 2011;17(5):345-54. Available at: http://www.jmcp.org/doi/10.18553/jmcp.2011.17.5.345.

15. Welch EK, Delate T, Chester EA, Stubbings T. Assessment of the impact of medication therapy management delivered to home-based Medicare beneficiaries. Ann Pharmacother. 2009;43(4):603-10.

16. Moczygemba L, Barner J, Lawson K, et al. Impact of telephone medication therapy management and health-related problems, medication adherence and Medicare Part D costs: a 6-month follow up. Am J Geriatr Pharmacother. 2011;9(5):328-38.

17. Moss J, Bryan W, Wilkerson L, et al. Impact of clinical pharmacy specialists on the design and implementation of a quality improvement initiative to decrease inappropriate medications in a Veteran Affairs emergency department. J Manag Care Spec Pharm. 2016;22(1):74-80. Available at: http://www. jmcp.org/doi/10.18553/jmcp.2016.22.1.74. 